\title{
A NANOSCALE SIMULATION STUDY OF ELASTIC PROPERTIES OF GASPEITE
}

\author{
BRAHIM-KHALIL BENAZZOUZ \\ Laboratoire des Fluides Complexes et leurs Réservoirs- LFC-R, UMR-5150, Université de Pau et des Pays de l'Adour, \\ BP 1155, 64013 PAU Cedex, France, e-mail: b.k.benazzouz@gmail.com
}

\begin{abstract}
The study of structural and mechanical properties of carbonate rock is an interesting subject in engineering and its different applications. In this paper, the crystal structure of gaspeite $\left(\mathrm{NiCO}_{3}\right)$ is investigated by carrying out molecular dynamics simulations based on energy minimization technique using an interatomic interaction potential.

At first, we focus on the structural properties of gaspeite mineral. And then, the elastic properties are calculated, including the elastic constants, bulk modulus, shear modulus, the S- and P-wave velocities. In the next part of this paper, the pressure effect will be studied on the structural and elastic properties of $\mathrm{NiCO}_{3}$ at high pressure.
\end{abstract}

Key words: carbonate rock, gaspeite, molecular dynamic, elastic properties, pressure effect

\section{INTRODUCTION}

Carbonate rocks are common minerals found in sedimentary environments. They have a general formula of $\mathrm{XCO}_{3}$ where $\mathrm{X}$ represents one or more metal ions (+2), such as $\mathrm{Ba}, \mathrm{Ca}, \mathrm{Cd}, \mathrm{Co}, \mathrm{Cu}, \mathrm{Fe}, \mathrm{Mg}, \mathrm{Mn}$, $\mathrm{Ni}, \mathrm{Pb}, \mathrm{Sr}, \mathrm{Zn}$ and others. The study of the elastic properties of carbonate rocks involves several engineering areas (civil engineering, petroleum engineering, etc.), i.e., the elastic properties of carbonate rock can be used as parameters in different geological and geomechanical models. These properties depend on several factors, including chemical composition, crystal orientation, pressure and temperature.

To study the gaspeite (or nickel carbonate mineral), molecular dynamics (MD) simulations based on energy minimization technique have been used. The DM simulation is a theoretical method used in the last two decades to study and evaluate a wide range of quantities (structural, physical, mechanical, thermodynamics, etc.) of materials.

Experimentally, the structural parameters and bulk modulus of gaspeite were reported for the first time by Zhang and Reeder [28] using energy-dispersive X-ray. Several studies by atomistic simulation have been published to evaluate the mechanical and structural properties of carbonate minerals. Structural properties, such as lattice parameters of carbonate minerals were evaluated by Pavese et al. [21], Leeuw and Parker
[17], Araujo et al. [1], Vinograd et al. [25], Sekkal et al. [24], Wang et al. [26], Benazzouz [4], the prediction of the elastic constants of calcite and aragonite by Jackson et al. [16], Pavese et al. [21], Cygan et al. [8], Rohl et al. [23], Archer et al. [2], Zaoui and Shahrour [27], the bulk modulus was determined by Catti et al. [7], Pavese et al. [21], Cygan et al. [8], Zaoui and Shahrour [27], Wang et al. [26]; Benazzouz [4].

In this paper, we present the elastic properties of gaspeite under normal conditions and under the effect of pressure. The paper is organized as follows. In Section 2, we describe the calculation details related to this study. In Section 3, we present the results and discussion. The last section contains conclusions.

\section{THEORETICAL BACKGROUND}

Many theoretical studies based on the atomic scale simulations have been made to develop interatomic potentials describing the carbonate rocks (Pavese et al. [20], Dove et al. [10], Jackson and Price [15], Catti et al. [7], Parker et al. [19], Fisler et al. [11], Archer et al. [2]. The interatomic potential based on the interaction of Rohl et al. [23] was used to describe the gaspeite.

In this study, a modified Born model for description of solids was used to perform simulations, in which the ionic material is treated as a collection of point ions with electrostatic and short-range forces 
Table 1. Adjusted potential parameters for gaspeite

\begin{tabular}{|c|c|c|c|c|}
\hline & \multicolumn{4}{|c|}{$U_{i j}^{\text {Buckingham }}=A \exp \left(-\frac{r_{i j}}{\rho}\right)-\frac{C}{r_{i j}^{6}}$} \\
\hline \multirow{5}{*}{$\begin{array}{l}\text { Buckingham } \\
\text { potential } \\
\text { (two-body) }\end{array}$} & & $A[\mathrm{eV}]$ & $P[\AA]$ & $C\left[\mathrm{eV} \AA^{6}\right]$ \\
\hline & $\mathrm{O}_{\mathrm{c}}-\mathrm{O}_{\mathrm{c}}$ (intra) & 4030.3 & 0.218 & 0 \\
\hline & $\mathrm{O}_{\mathrm{s}}-\mathrm{O}_{\mathrm{s}}$ (inter) & 214836.21 & 0.198 & 123.73 \\
\hline & $\mathrm{Ni}_{\mathrm{c}}-\mathrm{O}_{\mathrm{s}}$ & 1039.59 & 0.289 & 0 \\
\hline & $\mathrm{O}_{\mathrm{c}}-\mathrm{Ni}_{\mathrm{c}}$ & 26164795 & 0.12 & 0 \\
\hline & \multicolumn{4}{|c|}{$U_{i j}^{\text {Morse }}=D_{e}\left[\left(1-\exp \left(-a\left(r-r_{0}\right)\right)\right)^{2}\right]$} \\
\hline \multirow{3}{*}{$\begin{array}{l}\text { Morse } \\
\text { potential }\end{array}$} & & $D e[\mathrm{eV}]$ & $a\left[\AA^{-1}\right]$ & $r_{0}[\AA]$ \\
\hline & $\mathrm{C}_{\mathrm{c}}-\mathrm{O}_{\mathrm{c}}$ & 0.2485 & 2.523 & 1.198 \\
\hline & \multicolumn{4}{|c|}{$U_{i j k}^{\text {Three }}=\frac{1}{2} k_{2}\left(\theta_{i j k}-\theta_{0}\right)^{2}$} \\
\hline \multirow{3}{*}{$\begin{array}{l}\text { Three-body } \\
\text { potential }\end{array}$} & & $k_{2}\left[\mathrm{eV} / \mathrm{rad}^{2}\right]$ & $\theta_{0}\left[^{\circ}\right]$ & \\
\hline & $\mathrm{O}_{\mathrm{c}}-\mathrm{C}_{\mathrm{c}}-\mathrm{O}_{\mathrm{c}}$ & 1.799 & 120 & \\
\hline & \multicolumn{4}{|c|}{$U_{i j k l}^{\text {Four }}=k_{2} d^{2}+k_{4} d^{4}$} \\
\hline \multirow{3}{*}{$\begin{array}{l}\text { Four-body } \\
\text { potential }\end{array}$} & & $k_{2}\left[\mathrm{eV} / \AA^{2}\right]$ & $k_{4}\left[\mathrm{eV} / \AA^{4}\right]$ & \\
\hline & $\mathrm{O}_{\mathrm{c}}-\mathrm{C}_{\mathrm{c}}-\mathrm{O}_{\mathrm{c}}-\mathrm{O}_{\mathrm{c}}$ & 8.689 & 360 & \\
\hline & \multicolumn{4}{|c|}{$U_{i j}^{\text {Spring }}=\frac{1}{2} k_{2} r^{2}$} \\
\hline \multirow{2}{*}{$\begin{array}{l}\text { Spring } \\
\text { potential }\end{array}$} & & $k_{2}\left[\mathrm{eV} \cdot \mathrm{A}^{\circ-2}\right]$ & & \\
\hline & $\mathrm{O}_{\mathrm{c}}-\mathrm{O}_{\mathrm{s}}$ & 52.740 & & \\
\hline
\end{tabular}

acting between them (Born and Huang [5]). The contribution of the electrostatic interactions (longrange) is determined by using the Ewald sum whereas the short-range terms contribution for all ion-ion interaction of the crystal are summed within a predetermined cutoff. The procedure is described in detail by Catlow and Mackrodt [6]. The oxygen atom is represented by a core and a shell (Dick and Overhauser [9]). The harmonic spring potential is used for the core-shell. The interatomic potential model employed here is

$$
U=U_{i j}^{\text {Buckingham }}+U_{i j}^{\text {Morse }}+U_{i j}^{\text {Spring }}+U_{i j k}^{\text {Three }}+U_{i j k l}^{\text {Four }} .
$$

The potential forms are presented in Table 1. The forms are described in detail by Rohl et al. [23]. For the potential acting on the $\mathrm{CO}_{3}$ group, i.e., interactions with the outside of the Oxygen shell, there are intermolecular interactions of $\mathrm{O}-\mathrm{O}$ and Buckingham interaction of $\mathrm{Ni}-\mathrm{O}$. The interaction potentials between atoms of the same group $\mathrm{CO}_{3}$ (i.e., interactions with the oxygen core) are grouped $\mathrm{O}-\mathrm{O}$ intramolecular interactions and $\mathrm{C}-\mathrm{O}$ Morse interaction. A three-body term $(\mathrm{O}-\mathrm{C}-\mathrm{O})$ has been incorporated in the model, to maintain the $120^{\circ}$ bond angle in the $\mathrm{CO}_{3}$ group. A four-body potential $(\mathrm{O}-\mathrm{C}-\mathrm{O}-\mathrm{O})$ associated with the out-of-plane displacement of $\mathrm{C}$ within the $\mathrm{CO}_{3}$ group was added to the model. Buckingham potential is integrated between $\mathrm{Ni}-\mathrm{C}$ (Rohl et al. [23], Austen et al. [3]). All potential parameters used in this work were taken initially from the work of Rohl et al. [23].

Before we begin our calculation, some potential parameters are adjusted by using the GULP code, so as to minimize the sum of squared differences between the experimental and calculated properties (Gale [12], [13]). The experimental crystal structure (lattice parameters as $a, b, c, \alpha, \beta$ and $\gamma$ and fractional coordinates) and bulk modulus are the only parameters used during the fit; elastic constants are not taken into account. The adjusted parameters of the interatomic potentials are listed in Table 1.

$$
F=\sum_{i=1}^{N_{o b s}} \omega_{i}\left[f_{i}^{o b s}-f_{i}^{c a l c}\right]^{2} \rightarrow \min
$$

where $f_{\text {calc }}$ and $f_{\text {obs }}$ are the calculated and observed quantities and $\omega$ is a weighting factor.

In this study, the energy minimization technique is performed at constant pressure, which allows the atomic positions and lattice parameters to vary. The Newton-Raphson procedure is used to find the minima, with the Broyden-Fletcher-Goldfarb-Shanno (BFGS) scheme to update the Hessian (Gale [12], [13]). 


\section{RESULTS AND DISCUSSION}

\subsection{STRUCTURAL PROPERTIES}

Gaspeite structure used in this work is deduced from the crystallographic data of Pertlik [22], see Fig. 1, i.e., the crystal lattice is rhombohedral. The space group of gaspeite is " $R-3 c$ " with lattice parameters $a=4.612 \AA, b=4.612 \AA, c=14.735 \AA$, and angles: $\alpha=90^{\circ}, \beta=90^{\circ}, \gamma=120^{\circ}$, which gives a unit cell volume of $271.4 \AA^{3}$.

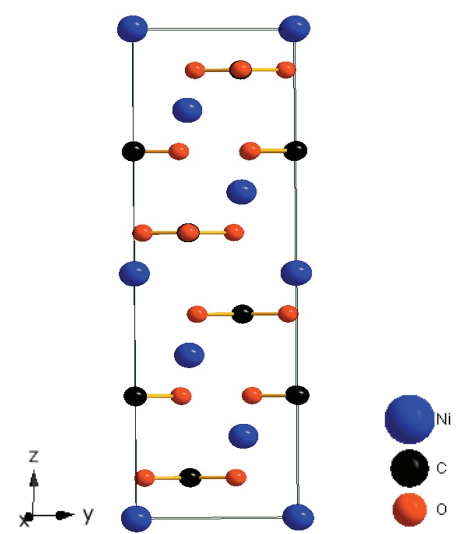

Fig. 1. Structure of gaspeite. $\mathrm{O}$ atoms are in red, $\mathrm{C}$ atoms are in black and $\mathrm{Ni}$ atoms in blue

The chemical composition of gaspeite is $\mathrm{NiCO}_{3}$. The $\mathrm{Ni}^{+2}$ atom is attached to an anionic group $\left(\mathrm{CO}_{3}^{-2}\right)$. The $\mathrm{CO}_{3}$ group, forming an equilateral triangle, consists of a carbon atom $(\mathrm{C})$ in the center and three oxygen atoms $(\mathrm{O})$ in each corner, see Fig. 2.

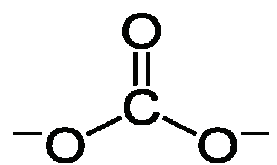

Fig. 2. Carbonate anion $\mathrm{CO}_{3}^{-2}$
Table 2 shows a comparison between experimental and calculated structural parameters of the gaspeite. We present a comparison of the initial $(a, b, c, \alpha, \beta$ and $\gamma$ from experiments) and the final (after fitting) configuration with the corresponding variation. The percentage difference between the lattice parameters of experimental and adjusted is acceptable. The report parameter c/a obtained is 3.19 which is in good agreement with the experimental values of 3.13 and 3.2 found by Pertlik [22], and Zhang and Reeder [28], respectively.

\subsection{MECHANICAL PROPERTIES}

In this work, we have used the mathematical formulation of the mechanical properties as given in the paper of Gale and Rohl [14]. The elastic constants are represented by the second derivative of the energy density with respect to strain

$$
C_{i j}=\frac{1}{V}\left(\frac{\partial^{2} U}{\partial \varepsilon_{i} \partial \varepsilon_{j}}\right)
$$

where $V$ is the volume, $U$ is the energy and $\varepsilon$ is the strain. Therefore, the elastic constant tensor is a $6 \times 6$ symmetric matrix. The 21 potentially independent matrix elements are usually reduced considerably by symmetry (Nye [18]). For a material rhombohedral, the matrix elements are $C_{11}, C_{33}, C_{44}, C_{12}, C_{13}, C_{14}$.

The elastic compliances $S$ can be readily calculated from the above expression by inverting the matrix (i.e., $S=C^{-1}$ ). The elastic compliances, $S_{i j}$, can be easily obtained from the above expression by inverting the matrix. The $C_{i j}$ and $S_{i j}$ obtained are given in Table 3. We note that $C_{33}$ is greater in value compared to other constants, which indicates that the gaspeite is stiffer in this direction.

In isotropic, polycrystalline aggregate, there are only two independent elastic constants, such as the bulk $(B)$ and shear $(G)$ moduli. Other constants are

Table 2. Comparison between the simulated and experimental structural properties of gaspeite

\begin{tabular}{|l|c|c|c|c|c|}
\hline & Experimental $^{\mathrm{a}}$ & This work & Variation (\%) & Exp $^{\mathrm{b}}$ & Theo $^{\mathrm{c}}$ \\
\hline Volume $\left(\AA^{3}\right)$ & 271.40 & 271.77 & 0.14 & 270.15 & 236.25 \\
\hline$a(\AA)$ & 4.6117 & 4.6463 & 0.75 & 4.60 & 4.33 \\
\hline$c(\AA)$ & 14.7350 & 14.5363 & -1.35 & 14.729 & 14.55 \\
\hline$c / a$ & 3.19 & 3.13 & & 3.2 & 3.36 \\
\hline$\alpha\left(^{\circ}\right)$ & 90.0 & 90.0 & 0.0 & & \\
\hline$\beta\left(^{\circ}\right)$ & 90.0 & 90.0 & 0.0 & & \\
\hline$\gamma\left({ }^{\circ}\right)$ & 120.0 & 120.0 & 0.0 & & \\
\hline
\end{tabular}

${ }^{\mathrm{a}}$ Pertlik 1986, ${ }^{\mathrm{b}}$ Zhang 1999, ${ }^{\mathrm{c}}$ Wang 2011. 
Table. 3. Calculated elastic moduli for gaspeite

\begin{tabular}{|c|c|c|c|c|c|c|}
\hline$C_{i j}$ & $C_{11}$ & $C_{33}$ & $C_{44}$ & $C_{12}$ & $C_{13}$ & $C_{14}$ \\
\hline This work & 217.81 & 298.99 & 82.69 & 51.87 & 97.93 & 27.60 \\
\hline$S_{i j}$ & $S_{11}$ & $S_{33}$ & $S_{44}$ & $S_{12}$ & $S_{13}$ & $S_{14}$ \\
\hline This work & 0.005822 & 0.004389 & 0.013604 & -0.000957 & -0.001594 & -0.002262 \\
\hline
\end{tabular}

Table. 4. Calculated $B, G, E, V_{s}, V_{p}$ and $v$ compared with previous theoretical calculation and available experimental data

\begin{tabular}{|l|c|c|c|}
\hline & This work & Experimental & Theoretical \\
\hline Bulk modulus $B(\mathrm{GPa})$ & 129.12 & $131^{\mathrm{a}}$ & $138^{\mathrm{b}}, 137^{\mathrm{c}}, 150^{\mathrm{d}}$ \\
\hline Shear modulus $G(\mathrm{GPa})$ & 73.89 & - & - \\
\hline$V_{p}(\mathrm{Km} / \mathrm{s})$ & 7.233 & - & - \\
\hline$V_{s}(\mathrm{Km} / \mathrm{s})$ & 4.121 & - & - \\
\hline$E(\mathrm{GPa})$ & $171.76,171.76,227.86$ & - & - \\
\hline$v$ & 0.260 & - & - \\
\hline \multicolumn{2}{|c|}{${ }^{\mathrm{a}}$ Zhang and Reeder [28], ${ }^{\mathrm{b}}$ Fisler et al. [11], ${ }^{\mathrm{c}}$ Austen et al. [3], ${ }^{\mathrm{d}}$ Wang et al. [26]. }
\end{tabular}

expressed in terms of $B$ and $G$. We are interested in calculating the value of $B$ ang $G$ from the values of $C_{i j}$ and $\underline{S}_{i j}$ using the relationships given in the work of Gale and Rohl [14].

The bulk modulus represents the ratio of the variation in pressure to the volume compression of a material.

$$
B=-V\left(\frac{\partial P}{\partial V}\right)_{T},
$$

$B$ is the bulk modulus, $P$ is the pressure, $V$ is the volume, and $T$ is the temperature.

Experimentally, the bulk modulus value for gaspeite of $131 \mathrm{GPa}$ was evaluated by Zhang and Reeder [28] using energy-dispersive X-ray, EDX. From energy minimization calculations, Fisler et al. [11], Austen et al. [3] and Wang et al. [26] reported the value of bulk modulus. The proposed values are a little larger than the experimental value. The bulk modulus, $B$, of gaspeite can be evaluated from the elastic compliances or elastic constants. The bulk modulus is given in equation (5) by two definitions, the lower (Reuss) bounds and the upper (Voigt) bounds (Gale and Rohl [14]). Using Reuss definition, the value obtained of $B=129.12 \mathrm{GPa}$ is in good trend with the only experimental values found in literature (Zhang and Reeder [28]). The bulk modulus (Voigt) obtained is $136.68 \mathrm{GPa}$.

The shear modulus describes the response of materials to deformation in shear. It can also be calculated employing the Reuss and Voigt definitions (see equations (6)). The values obtained for shear modulus are $73.89 \mathrm{GPa}$ and $82.13 \mathrm{GPa}$ using the Reuss and Voigt definitions, respectively.

$$
B_{\text {Reuss }}=\left(S_{11}+S_{22}+S_{33}+2\left(S_{12}+S_{13}+S_{23}\right)\right)^{-1}
$$

and

$$
\begin{gathered}
B_{\text {Voigt }}=\frac{1}{9}\left(C_{11}+C_{22}+C_{33}+2\left(C_{12}+C_{13}+C_{23}\right)\right), \\
G_{\text {Reuss }}=\frac{15}{4}\left(\left(S_{11}+S_{22}+S_{33}-S_{12}-S_{13}-S_{23}\right)\right. \\
\left.+3\left(S_{44}+S_{55}+S_{66}\right)\right)^{-1}
\end{gathered}
$$

and

$$
\begin{gathered}
G_{\mathrm{Voigt}}=\frac{1}{15}\left(C_{11}+C_{22}+C_{33}+3\left(C_{44}+C_{55}+C_{66}\right)\right. \\
\left.-C_{12}-C_{13}-C_{23}\right),
\end{gathered}
$$

where $S_{i j}$ and $C_{i j}$ are the elastic compliances and elastic constants, respectively, given in Table 4.

The next property determined is Young's modulus. Young's modulus is defined by the ratio of stress to strain. It can be calculated from the elastic compliances in three Cartesian directions $a, b$ and $c$ (Gale and Rohl [14]). The values obtained for gaspeite crystal are $E_{x}=S_{11}^{-1}=171.76 \mathrm{Gpa}, E_{y}=S_{22}^{-1}$ $=171.76 \mathrm{GPa}$ and $E_{y}=S_{33}^{-1}=227.86 \mathrm{GPa}$. Concerning the acoustic wave velocities (acoustic transverse wave velocity, $V_{s}$, and longitudinal wave velocity, $V_{p}$ ) and the Poisson ratio can be calculated from $B$ and $G$ as follows

$$
V_{s}=\sqrt{\frac{G}{\rho}}, \quad V_{p}=\sqrt{\frac{4 G+3 B}{3 \rho}} \text { and } v=\frac{3 B-2 G}{2(3 B+G)} .
$$


The obtained $V_{p}, V_{s}$ and $v$ are $7.233,4.121 \mathrm{kms}^{-1}$ and 0.26 , respectively.

The calculated mechanical quantities for gaspeite, bulk modulus, shear modulus, Young's moduli, elastic wave velocities $\left(V_{s}\right.$ and $\left.V_{p}\right)$ and the Poisson ratio, are summarized in Table 4 compared to experimental findings and theoretical works.

\subsection{PRESSURE EFFECT}

Understanding the rocks mineral behavior depending on earth depth can be combined with knowl-

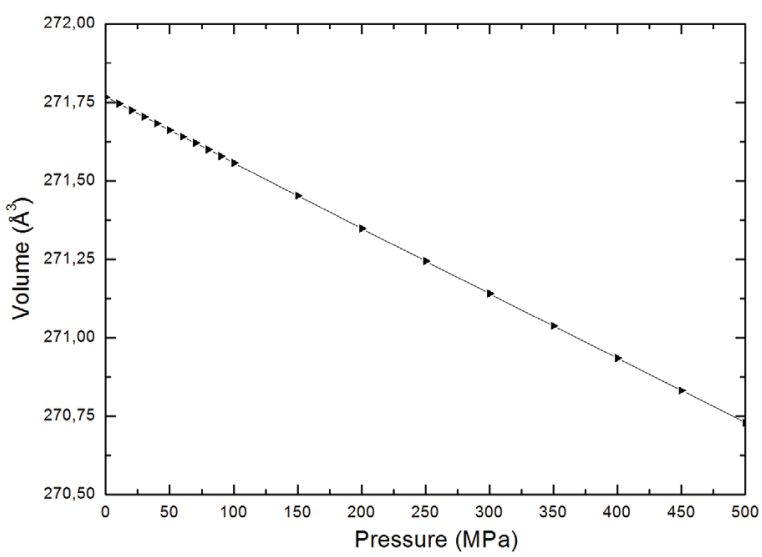

edge of the physical quantities. We then focused on the evaluation of these properties and we studied their variation under the effect of hydrostatic pressure using molecular dynamics simulations. The behavior under pressure of gaspeite is presented in a range from 0 to $500 \mathrm{MPa}$ corresponding to depths greater than $10 \mathrm{~km}$.

\section{EFFECT ON THE STRUCTURAL PROPERTIES}

Figures 3 and 4 depict the variation of volume, density, the cell parameters $a, b, c$ and angles $\alpha, \beta$ and $\gamma$ with pressure. The slope value of decrease in

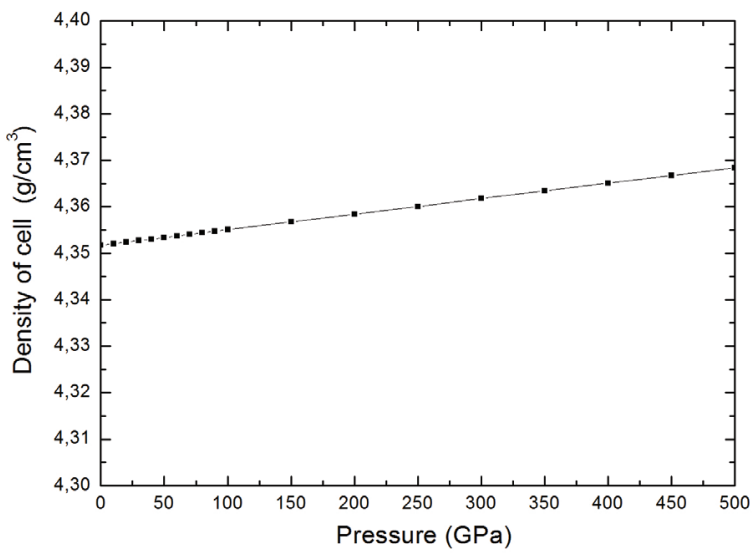

Fig. 3. Volume and density variation of gaspeite with pressure
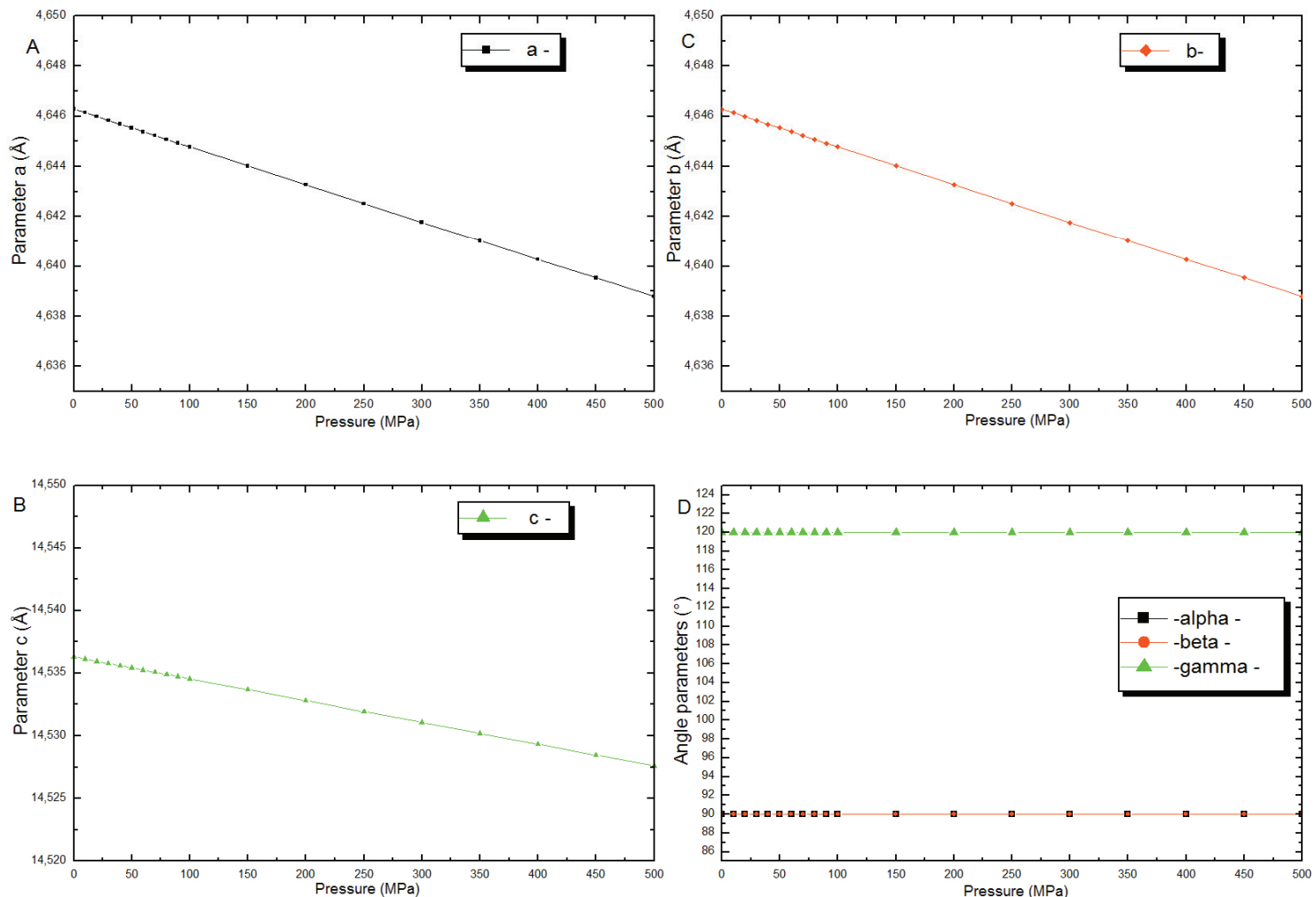

Fig. 4. The $a, b, c, \alpha, \beta$ and $\gamma$ of gaspeite as a function of pressure 
volume is 1.77 , which is almost the same slope (equal to 1.83 ) that represents the volume variation in the work of Zhang and Reeder [28]. Zhang and Reeder studied the pressure effect on the $\mathrm{NiCO}_{3}$ in the interval from 0 to $7.29 \mathrm{GPa}$. We notice that the density increases with pressure up to $4.37 \mathrm{~g} / \mathrm{cm}^{3}$.

The decrease of the lattice parameters $a, b$ and $c$ is observed with pressure and stability of $\alpha, \beta$ and $\gamma$ angles. The pressure effect on $a(=b)$ and $c$ parameters of gaspeite can be compared to the experimental work of Zhang and Reeder [28]. The variation of $a$ and $c$ axes with pressure is given by: $a=4.6463-2 \mathrm{E}-05^{*} P$ and $c=14.536-2 \mathrm{E}-05^{*} P$, where $\mathrm{P}$ is the pressure in $\mathrm{GPa}$, and the axis length is in $\AA$.

\section{EFFECT ON THE MECHANICAL PROPERTIES}

In this section, the effect of hydrostatic pressure on the mechanical properties of gaspeite is presented. Pressure dependence of the elastic constants of gaspeite is shown in Fig. 5. The elastic constants are almost stable with a slight increase for $C_{11}$ and $C_{33}$. From 0 to $500 \mathrm{MPa}$, the $C_{33}$ (corresponding to the $c$-axis perpendicular to the atomic planes) is greater than $C_{11}$ corresponding to the $a$-axis, which shows that this structure is more compressive in the direction perpendicular to the layers parallel to (100) plane. The potential energy has contributed to reduction of the volume of the unit cell and increase of the stiffness constants.

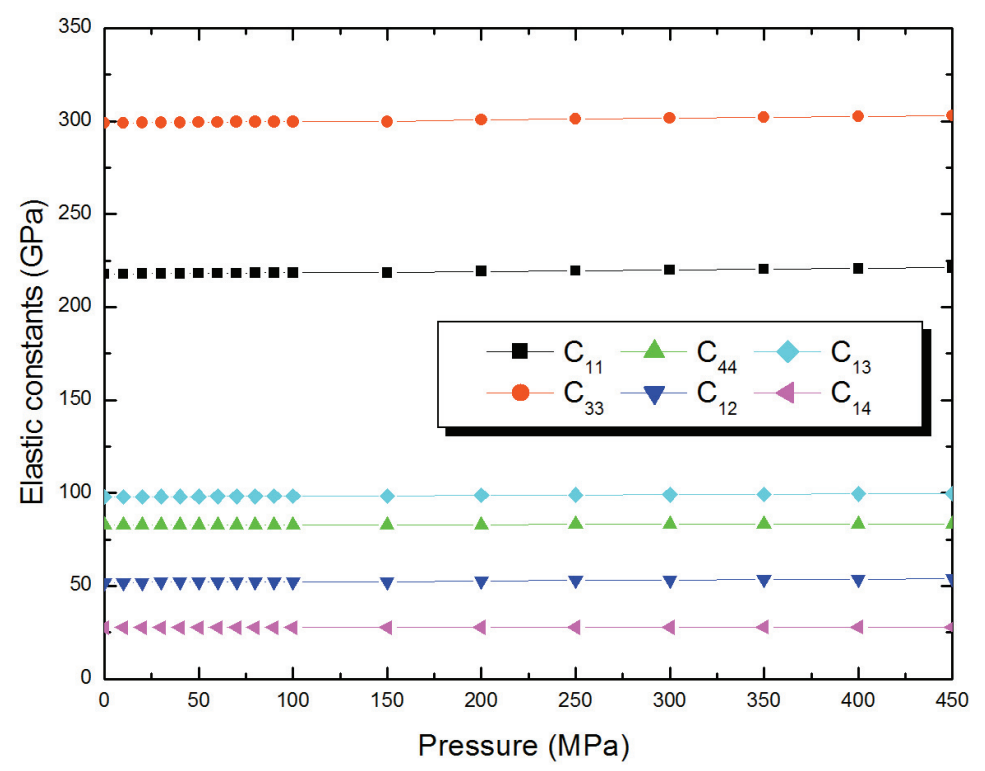

Fig. 5. Elastic constants as function of pressure for gaspeite:

$$
C_{11}, C_{33}, C_{44}, C_{12}, C_{13}, C_{14}
$$
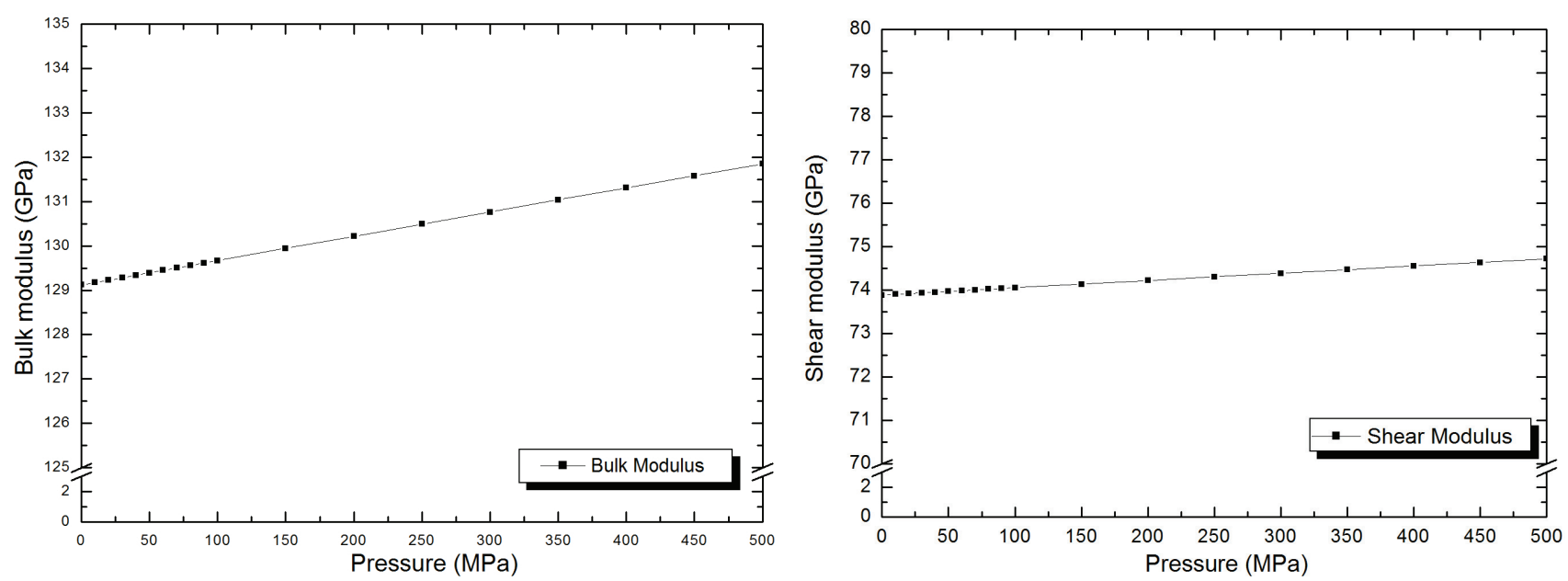

Fig. 6. Bulk modulus (left image) and shear modulus (right image) of gaspeite with pressure 
Figure 6 illustrates a pressure dependence of the isotropic bulk $(B)$ and shear $(G)$ moduli. A linear increase presents that the gaspeite becomes more rigid in this pressure range. The bulk modulus increases from 129 GPa up to $132 \mathrm{GPa}$. The increase of the bulk modulus is more significant than that for shear modulus. velocity, $V_{p}$. Under pressure, gaspeite became more rigid and this is represented by the slight increase in the value of the elastic wave velocities. Finally, Fig. 7 shows the evolution of azimuthal anisotropy $A_{s}$ and $A_{p}$ as a function of pressure. The $A_{s}$ and $A_{p}$ waves are defined as

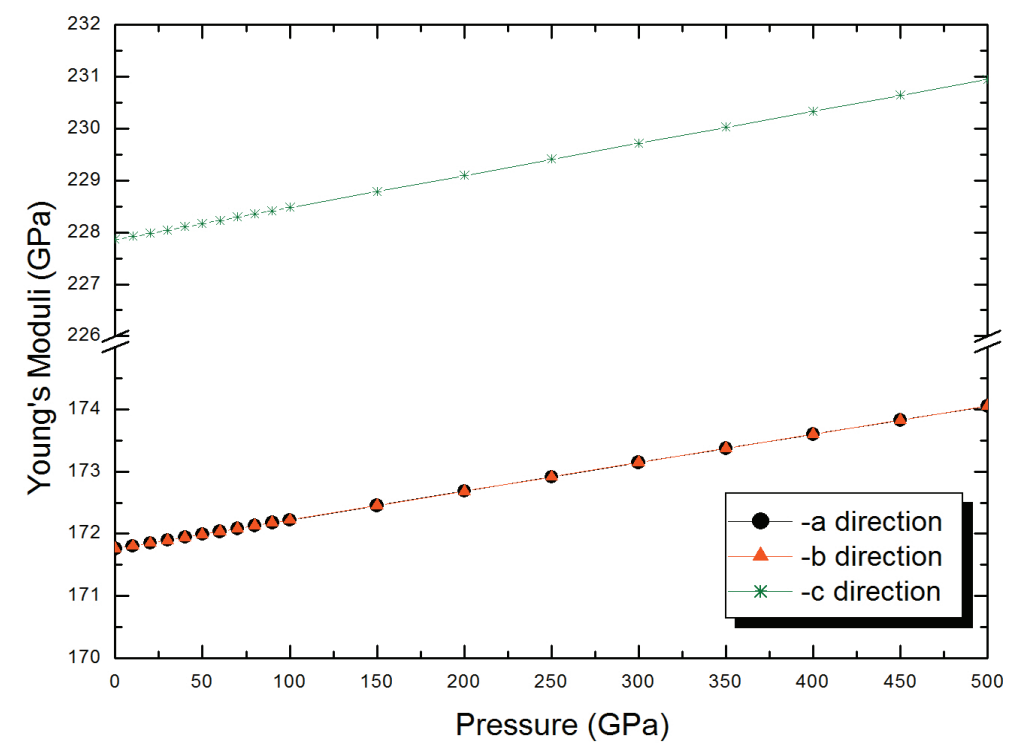

Fig. 7. Young's modulus of gaspeite as a function of pressure along $a, b$, and $c$ directions
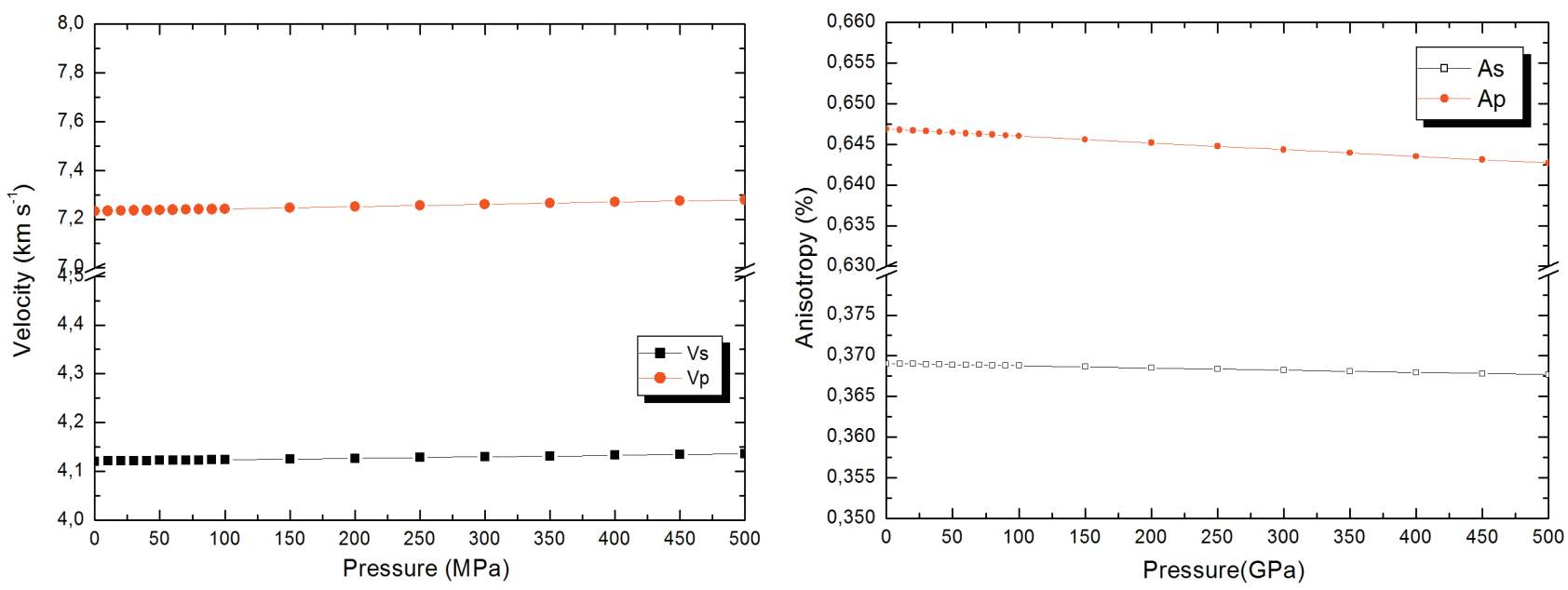

Fig. 8. Comparison between $P$-wave velocity and $S$-wave velocity (left image) and anisotropy (right image) with pressure for gaspeite

The variation in Young's modulus with pressure is shown in Fig. 7. Young's modulus increases linearly in the three directions up to the pressure of $500 \mathrm{MPa}$. This can be explained from the fact that its crystallographic structure is composed of planes of nickel ions along the $c$ direction alternately with the carbonate groups $\mathrm{CO}_{3}$.

Figure 8 illustrates a linear variation of the transverse wave velocity, $V_{s}$, and the longitudinal wave

$$
A_{p}=\left(\frac{V_{P_{\max }}-V_{P_{\min }}}{V_{P}}\right) * 100
$$

and

$$
A_{S}=\left(\frac{V_{S_{\max }}-V_{S_{\min }}}{V_{S}}\right) * 100
$$




\section{CONCLUSION}

In this work, the molecular dynamics based on energy minimization approach was employed to study the gaspeite (nickel carbonate). Potential fitting has been used in order to make calculation reliable. The potential fitting was made considering the experimental value of the bulk modulus of gaspeite $131 \mathrm{GPa}$ (Zhang and Reeder [28]).

The structural and mechanical properties were performed at atmospheric pressure. The values of bulk modulus and shear modulus were evaluated as 129.12 GPa and $73.89 \mathrm{GPa}$, respectively. In the next step, the pressure effect was introduced to predict the behavior of these properties. The results are in good agreement with available experimental measurements and some theoretical work.

\section{REFERENCES}

[1] Araujo R.M., ERnesto M., Giroldo V., Computer simulation of static defects generated by the metals substitutional $\mathrm{CaCO}_{3}$, thesis, Department of Physics at the Federal University of Sergipe, Brasil, 2004.

[2] ArCher T.D., Birse S.E.A., Dove M.T. et al., An interatomic potential model for carbonates allowing for polarization effects, Phys. Chem. Minerals, 2003, 30, 416-424.

[3] Austen K.F., Wright K., Slater B., Gale J.D., The interaction of dolomite surfaces with metal impurities: A Computer Simulation Study, Phys. Chem. Chem. Phys., 2005, 7, 4150-4156.

[4] Benazzouz B.-K., Etude théorique des propriétés structurales et mécaniques de la roche rhodochrosite, 31ème Rencontres Universitaires de Génie Civil, Cachan, 2013.

[5] Born M., Huang K., Dynamical theory of crystal lattices, Oxford University Press, Oxford, 1954.

[6] Catlow C.R.A., MaCKRODT W.C., Computer Simulation of Solids, 320, p. Berlin, Springer-Verlag, 1982.

[7] Catti M., Pavese A., Price G.D., Thermodynamic properties of $\mathrm{CaCO}_{3}$ calcite and aragonite: a quasi-harmonic calculation, Phys. Chem. Miner., 1993, 19, 472-479.

[8] Cygan R.T., Wright K., Fisler D.K., Gale J.D., Slater B., Atomistic models of carbonate minerals: bulk and surface structures, defects, and diffusion, Molecular Simulation, 2002, Vol. 28 (6-7), 475-495.

[9] Dick B.G., OvERHAUSER A.W., Theory of the dielectric constants of alkalihalide crystals, Physical Review, 1958, 112, 90-103.

[10] Dove M.T., Winkler B., Leslie M., Harris M.J., SALJE E.K.H., A new interatomic potential model for calcite: applications to lattice dynamics studies, phase transition, and isotopic fractionation, Am. Mineral., 1992, 77, 244-250.
[11] Fisler D.K., Gale J.D., Cygan R.T. et al., A shell model for the simulation of rhombohedral carbonate minerals and their point defects, Am. Mineral., 2000, 85, 217-224.

[12] Gale J.D., Empirical potential derivation for ionic materials, Phil. Mag. B, 1996, 73, 3.

[13] GALE J.D., GULP: A computer program for the symmetryadapted simulation of solids, J. Chem. Soc. Faraday Trans., 1997, 93, 629-637.

[14] GaLe J.D., RoHL A.L., The general utility lattice program (gulp), Molecular Simulation, 2003, Vol. 29 (5), 291-341.

[15] JACKSON R.A., PrICE G.D., A transferable interatomic potential for calcium carbonate, Molecular Simulation, 1992, 9, $75-177$.

[16] Jackson R.A., MeEnan P.A., Price G.D. et al., Deriving empirical potentials for molecular ionic materials, Mineral. Mag., 1995, 59, 617-622.

[17] LeEUw N.H., PARKer S.C., Modeling absorption and segregation of magnesium and cadmium ions to calcite surfaces: Introducing $\mathrm{MgCO}_{3}$ and $\mathrm{CdCO}_{3}$ potential models, Journal of Chemical Physics, 2000, Vol. 112, No. 9.

[18] Nye J.F., Physical properties of crystals, Oxford University Press, 1985.

[19] Parker S.C., Titiloye J.O., Watson G.W., Phil. Trans. R Soc. London, Ser. A Phys. Sci. Eng. 1993, 344, 37.

[20] Pavese A., CATti M., Price G.D. et al., Interatomic potentials for $\mathrm{CaCO}_{3}$ polymorphs (calcite and aragonite), fitted to elastic and vibrational data, Phys. Chem. Minerals, 1992, 19, 80-87.

[21] Pavese A., Catti M., Parker S.C., Wall A., Modelling of the thermal dependence of structural and elastic properties of calcite, $\mathrm{CaCO}_{3}$, Phys. Chem. Minerals, 1996, 23, 89-93.

[22] Pertlik, , Structures of hydrothermally synthesized cobalt (II) carbonate and nickel(II) carbonate, Acta Cryst., 1986, C42, 4-5.

[23] Rohl A.L, Wright K., Gale J.D., Evidence from surface phonons for the $(2 \times 1)$ reconstruction of the $(10-14)$ surface of calcite from computer simulation, American Mineralogist, 2003, Vol. 88, 921-925.

[24] SekKal W., Taleb N., Zaoui A., Shahrour I., A lattice dynamical study of the aragonite and post-aragonite phases of calcium carbonate rock, American Mineralogist, 2008, Vol. 93, 1608-1612.

[25] Vinograd V.L, Winkler B., Putnis A., Gale J.D., SLUITER M.H.F., Static lattice energy calculations of mixing and ordering enthalpy in binary carbonate solid solutions, Chemical Geology, 2006, 225, 304-313.

[26] Wang Q., Grau-Crespo R., De Leeuw N.H., Mixing Thermodynamics of the Calcite-Structured ( $\mathrm{Mn}, \mathrm{Ca}) \mathrm{CO}_{3}$ Solid Solution: A Computer Simulation Study, J. Phys. Chem. B, 2011, 115, 3854-13861.

[27] ZaOUI A., Shahrour I., Molecular dynamics study of highpressure polymorphs of $\mathrm{BaCO}_{3}$, Philosophical Magazine Letters, 2010, Vol. 90, No. 9, 689-697.

[28]Zhang J., REEDER R.J., Comparative compressibilities of calcite-structure carbonates: Deviations from empirical relations, American Mineralogist, 1999, 84, 861-870. 